\title{
Post-Endodontic Treatment Flare-Up of Patients Treated By General Dentists and Endodontic Specialists
}

\author{
Alzahrani $\mathrm{MS}^{1 *}$, Alzahrani $\mathrm{AAH}^{2}$, Alhuwairini $\mathrm{SM}^{3}$, Bushyah $\mathbf{M}^{3}$, \\ Alawadhi AM${ }^{4}$, Alghamdi SA ${ }^{5}$, Korayem $\mathbf{M}^{6}$ and Alghamdi SG $^{7}$ \\ ${ }^{1}$ Department of Restorative Dental Sciences, Albaha University, Saudi Arabia \\ ${ }^{2}$ Dental Health Department,Faculty of Applied Medical Sciences, Albaha university, Albaha, \\ Saudi Arabia \\ ${ }^{3}$ General Dentist, Albaha Dental Center, Ministry of Health, Saudi Arabia \\ Research Article \\ Volume 6 Issue 4 \\ Received Date: October 06, 2021 \\ Published Date: October 21, 2021 \\ DOI: $10.23880 /$ oajds-16000315 \\ ${ }^{4}$ Restorative Dentistry Specialist, Albaha Dental Center, Saudi Arabia \\ ${ }^{5}$ Endodontic Specialist, Albaha Dental Center, Saudi Arabia \\ ${ }^{6}$ Preventive Dental Sciences department, Faculty of Dentistry, Albaha University, Albaha, Saudi Arabia \\ ${ }^{7}$ Dental Hygienist, Albaha Dental Center, Saudi Arabia
}

*Corresponding author: Mohammed Sarhan Alzahrani, Assistant Professor, Endodontic Consultant, Restorative Dental Sciences Department, Faculty of Dentistry, Albaha University, Albaha, Saudi Arabia, Tel: 00966543291242; Email: m.sarhan@bu.edu.sa

\section{Abstract}

Objective: This study aims to determine post-endodontic flare-up incidence for patients treated by endodontic specialists and general dental practitioners.

Methods: The investigators measured the postoperative pain using a visual analog scale after 24 and 48 hours for patients treated endodontically by specialists and general dentists. The patient factors and operative variables were documented for every patient. The data was then analyzed using SPSS. A Chi-square test was used to evaluate a relationship between categorical variables, where a $\mathrm{P}<0.05$ was taken to indicate statistical significance.

Results: In total, 143 participants were included in this study (male: $n=62,43.3 \%$; and female: $n=81,56.7 \%$ ). The incidence of post-endodontic treatment flare-ups was $14.8 \%$. The incidence of 48 hours postoperative pain was higher $(29 \%)$ with the endodontic specialists compared to the general practitioners. The factors that were associated with a higher postoperative flare-up include; patient age, smoking, preoperative pain, and periapical lesion size.

Conclusion: Post-endodontic flare-up incidence in this study was within the reported range of flare-up. Patient factors are associated with the occurrence of the postoperative flare-up more than the operative factors.

Keywords: Post Endodontic Flare-Up; Pain Scale; Root Canal Treatment

Abbreviations: CONSORT: Consolidated Standards of Reporting Trials.

\section{Introduction}

Post-endodontic treatment flare-up is not an uncommon complication that bothers both the patient and the treating dentist $[1,2]$. According to the American
Association of Endodontics, flare-up could be defined as an acute exacerbation of an asymptomatic pulpal and/or periradicular pathosis after initiation or continuation of root canal treatment [3].

The reported incidence of the post-endodontic flareup in the literature range from $2 \%-20 \%$, with an average, reported incidence of $8.4 \%[1,2]$. The differences could be 
correlated to the various research protocols, such as the sample's inclusion criteria or pain stage evaluation criteria. Furthermore, this difference might be due to the difference in definitions of a post-endodontic flare-up between the studies. The post-endodontic flare-up is a multifactorial complication where multiple variables play roles in its occurrence and intensity. Various studies have investigated different factors that can be correlated to the occurrence of this condition $[4,5]$. It has been found that microbial, host, and treatment procedure factors could affect the incidence and severity of post-endodontic pain [5].

The visual analog scale is one of the most frequently used instruments for measurement of pain intensity. Pain scores are based on patient-self measurement of symptoms that are recorded with a handwritten mark placed at one point along the length of a $100-\mathrm{mm}$ line that represents a continuum between the two ends of the scale "no pain" on the left end $(0$ $\mathrm{mm}$ ) of the scale and the "worst pain" on the right end of the scale $(100 \mathrm{~mm})$. Measurements from the left starting point to the patients' marks are recorded in millimeters and are interpreted as their pain intensity. The values can be used to track pain intensity for a patient or to compare pain between patients with similar conditions [6].

Evidence has shown that postoperative endodontic pain was associated with patients' dental phobia from a dental public health perspective [7]. However, reducing dental phobia level could be achieved by providing those patients with sufficient information regarding the expected endodontic pain before, during, and after the therapy. Therefore, this clinical study aims to determine the incidence of post-endodontic flare up and the associated effect of operative and patient factors on patients treated by endodontic specialists and general dental practitioners.

\section{Material and Methods}

The study and informed consent forms were approved by the research and ethics committee (Ethical Approval \#1002320). Patients were scheduled from the waiting. Medically compromised patients were excluded from the study. Teeth with severe periodontitis were excluded as well.

All patients were informed of the study's aims and design and written informed consent was obtained from each participant before their inclusion. The patients were randomly assigned to two general dentists and two endodontists as shown in the Consolidated Standards of Reporting Trials (CONSORT) flow diagram in Figure 1. All patients received endodontic treatment at the Specialty Dental Center. Patients were assessed for the level of discomfort or pain before and after receiving an endodontic therapy according to a standardized visual analog pain scale and specific time interval. Moderate and severe levels of pain and/or swelling were considered as an endodontic flare-up. A second examiner has followed up with every patient to calibrate the pain and swelling 24 hours and 48 hours after the endodontic treatment.

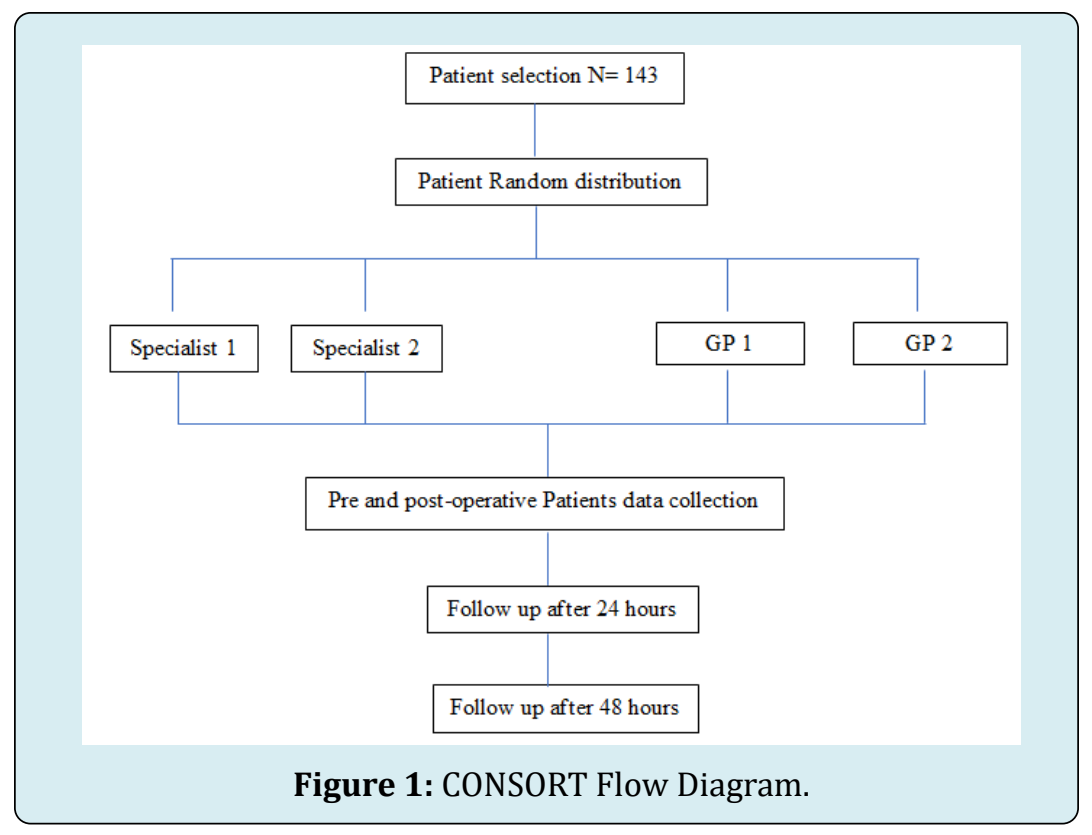

Each patient's record consisted of the following data: gender; age; smoking history; tooth category; pulpal and periradicular diagnosis; the intensity of preoperative pain if present; the size of the periapical lesion; type of treatment procedure; the number of visits utilized; whether the calcium hydroxide was used as an intracanal medicament or not and 
whether or not apical patency was maintained.

\section{Statistical Analysis}

The data were collected, and the significance level was chosen as 0.05. SPSS Version 22, (Armonk, New York, U.S.A.) was used to analyze the data. A Chi-square test was used to evaluate a relationship between categorical variables, where a $\mathrm{P}<0.05$ was taken to indicate statistical significance.

\section{Results}

A total of 143 patients (62 male and 81 female) were included in this study. The incidence of post-endodontic treatment flare-up was $14.8 \%$ of the treated cases (Table 1).

\begin{tabular}{|c|c|c|}
\hline \multirow{2}{*}{} & \multicolumn{2}{|c|}{ Post-endodontic Flare-up } \\
\cline { 2 - 3 } & Yes & No \\
\hline Pain in 24hours & $14.80 \%$ & $85.20 \%$ \\
\hline Pain in 48 hours & $14.10 \%$ & $85.90 \%$ \\
\hline Swelling & $6.70 \%$ & $93.30 \%$ \\
\hline
\end{tabular}

Table 1: Overall incidence of post-endodontic Flare-up.

\section{Patient Factors and Postoperative Flare-Up (Table 2)}

- Although the postoperative pain was slightly higher with male patients $(17.8 \%)$ compared to the female patients $(12 \%)$, the difference was statistically insignificant.

- The 48 hours postoperative pain of the patient with the age group of $20-40$ was high $(24.1 \%)$ compared to the other age groups, and the difference was a statistically significant $P$ value $(0.043)$.

- There was no statically significant difference in the incidence of postoperative pain between the patient with good, fair, or poor oral hygiene.

- The incidence of 48 hours postoperative pain for smokers was significantly high (33.4\%).

- Also, the postoperative swelling was remarkably high with smoker patients $(26.7 \%)$.

- The reported 24-48 hours postoperative pain was increased with the upper posterior teeth (19.2\%-17.5\%) and the lower anterior teeth (33.3\%). However, only three lower anterior teeth were included in this study (Table 2).

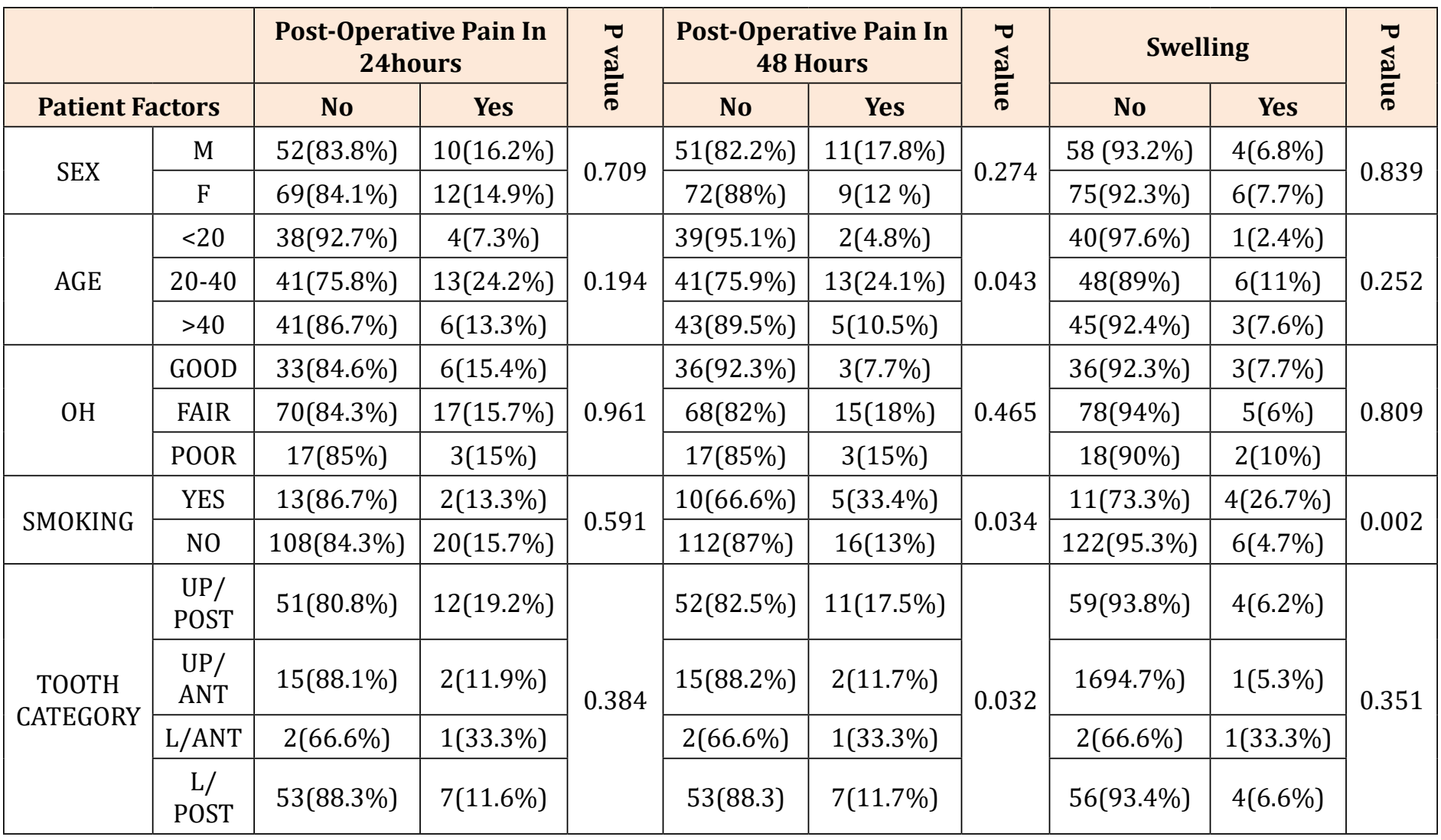

Table 2: Patient factors and the postoperative flare up. 


\section{Diagnostic Factors and Postoperative Flare-Up (Table 3)}

- No statistically significant difference was reported regarding the postoperative pain and swelling with the pulpal diagnosis as shown in Table 2.

- The reported incidence of postoperative pain and swelling was higher in patients with the periapical diagnosis of an acute and chronic apical abscess, as shown in Table 2.

- The postoperative swelling was more increased (27.3\%) and statistically significant in patients with periapical lesion size more than $5 \mathrm{~mm}$.

- The postoperative swelling was associated more with moderate preoperative pain $(22.7 \%)$, and the difference was a significant $P$ value $(0.023)$.

\begin{tabular}{|c|c|c|c|c|c|c|c|c|c|c|}
\hline & & \multicolumn{2}{|c|}{$\begin{array}{c}\text { Post-Operative Pain In } \\
24 \text { Hours }\end{array}$} & \multirow{2}{*}{ Ðٌ } & \multicolumn{2}{|c|}{$\begin{array}{c}\text { Post-0perative Pain In } \\
48 \text { Hours }\end{array}$} & \multirow{2}{*}{ ઇ } & \multicolumn{2}{|c|}{ Swelling } & \multirow{2}{*}{ 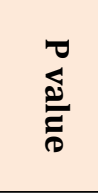 } \\
\hline \multicolumn{2}{|c|}{$\begin{array}{l}\text { Diagnostic } \\
\text { Factors }\end{array}$} & No & Yes & & No & Yes & & No & Yes & \\
\hline \multirow{7}{*}{ Pulp Dx } & Normal & $1(100 \%)$ & 0 & \multirow{7}{*}{0.692} & $1(100 \%)$ & 0 & \multirow{7}{*}{0.793} & $1(100 \%)$ & 0 & \multirow{7}{*}{0.835} \\
\hline & R.P. & $5(83.3 \%)$ & $1(16.7 \%)$ & & $4(66.7 \%)$ & $2(33.3 \%)$ & & $6(100 \%)$ & 0 & \\
\hline & SIP & $33(89.2 \%)$ & $4(10.8 \%)$ & & $35(94.6 \%)$ & $2(5.4 \%)$ & & $36(97.3 \%)$ & $1(2.7 \%)$ & \\
\hline & AIP & $6(100 \%)$ & 0 & & $6(100 \%)$ & 0 & & $6(100 \%)$ & 0 & \\
\hline & N.E.C. & $16(80 \%)$ & $4(20 \%)$ & & $17(85 \%)$ & $3(15 \%)$ & & $18(90 \%)$ & $2(10 \%)$ & \\
\hline & PREV.I & $41(80 \%)$ & $10(20 \%)$ & & $40(78.4 \%)$ & $11(21.6 \%)$ & & $45(88.2 \%)$ & $6(11.8 \%$ & \\
\hline & P R.C.T. & $15(83.4 \%)$ & $3(16.6 \%)$ & & $15(83.4 \%)$ & $3(16.6 \%)$ & & $17(94.4 \%)$ & $1(5.6 \%)$ & \\
\hline \multirow{5}{*}{ P.A. Dx } & Normal & $21(84 \%)$ & $4(16 \%)$ & \multirow{5}{*}{0.733} & $22(88 \%)$ & $3(12 \%)$ & \multirow{5}{*}{0.961} & $25(100 \%)$ & 0 & \multirow{5}{*}{0.277} \\
\hline & SAP & $73(85.5 \%)$ & $16(14.5 \%)$ & & $59(85.5 \%)$ & $10(14.5 \%)$ & & $63(91.3 \%)$ & $6(7.7 \%)$ & \\
\hline & A.A.P. & $22(88 \%)$ & $3(12 \%)$ & & $21(84 \%)$ & $4(16 \%)$ & & $24(96 \%)$ & $1(4 \%)$ & \\
\hline & AAA & $8(80 \%)$ & $2(20 \%)$ & & $9(90 \%)$ & $1(10 \%)$ & & $8(80 \%)$ & $2(20 \%)$ & \\
\hline & CAA & $9(81.8 \%)$ & $2(18.2 \%)$ & & $9(81.8 \%)$ & $2(18.2 \%)$ & & $10(90.9 \%)$ & $1(9.1 \%)$ & \\
\hline \multirow{3}{*}{ PAI } & normal & $67(82.8 \%)$ & $14(17.2 \%)$ & \multirow{3}{*}{0.168} & $65(80 \%)$ & $16(20 \%)$ & \multirow{3}{*}{0.494} & $77(95.1 \%)$ & $4(4.9 \%)$ & \multirow{3}{*}{0.01} \\
\hline & $<5 \mathrm{~mm}$ & $30(85.7 \%)$ & $5(14.3 \%)$ & & $33(94.3 \%)$ & $2(5.7 \%)$ & & $34(97.1 \%)$ & $1(2.9 \%)$ & \\
\hline & $>5 \mathrm{~mm}$ & $9(81.9 \%)$ & $2(18.2 \%)$ & & $9(81.8 \%)$ & $2(18.2 \%)$ & & $8(72.7 \%)$ & $3(27.3 \%)$ & \\
\hline \multirow{4}{*}{$\begin{array}{l}\text { PREOP. } \\
\text { PAIN }\end{array}$} & NON & $40(85 \%)$ & $7(15 \%)$ & \multirow{4}{*}{0.167} & $40(85.1 \%)$ & $7(14.9 \%)$ & \multirow{4}{*}{0.527} & $45(95.7 \%)$ & $2(4.3 \%)$ & \multirow{4}{*}{0.023} \\
\hline & MILD & $17(81 \%)$ & $4(19 \%)$ & & $18(85.7 \%)$ & $3(14.3 \%)$ & & $20(95.2 \%)$ & $1(4.8 \%)$ & \\
\hline & M.O.D. & $19(86.3 \%)$ & $3(13.7 \%)$ & & $18(81.8 \%)$ & $4(18.2 \%)$ & & $17(77.3 \%)$ & $5(22.7 \%)$ & \\
\hline & S.E.V. & $42(84 \%)$ & $8(16 \%)$ & & $43(86 \%)$ & $7(14 \%)$ & & $48(96 \%)$ & $2(4 \%)$ & \\
\hline
\end{tabular}

Table 3: Diagnostic factors and the postoperative flare up.

\section{Operative Factors and Postoperative Flare-Up (Table 4).}

- Although the 24-48 hours postoperative pain was reported more in obturation cases (20\%-25\%), the difference between the reported postoperative pain and swelling of the variable treatment procedures was insignificant, as shown in Table 3.

- The reported rate of 24-48 hours postoperative pain in cases with maintained patency was (24\%-26\%) respectively.
- In the 24 hours, postoperative pain incidence was slightly higher in cases with calcium hydroxide (16.9\%).

- However, the postoperative pain was higher in the 48 hours in cases without calcium hydroxide (19\%).

- The postoperative swelling was significantly higher in patients that were treated in multiple visits $(21.4 \%)$. The incidence of 48 hours postoperative pain was higher (29\%) with one of the endodontic specialists compared to the other specialist and the general practitioners (Table 4). 


\begin{tabular}{|c|c|c|c|c|c|c|c|c|c|c|}
\hline & & \multicolumn{2}{|c|}{$\begin{array}{l}\text { Post-Operative Pain } \\
\text { In 24hours }\end{array}$} & \multirow{2}{*}{ ఫ্ঠ } & \multicolumn{2}{|c|}{$\begin{array}{l}\text { Post-Operative Pain } \\
\text { In } 48 \text { Hours }\end{array}$} & \multirow{2}{*}{ ฮ્ฮ } & \multicolumn{2}{|c|}{ Swelling } & \multirow{2}{*}{ 苞 } \\
\hline \multicolumn{2}{|c|}{ Operative Factors } & No & Yes & & No & Yes & & No & Yes & \\
\hline \multirow{4}{*}{$\begin{array}{c}\text { TX } \\
\text { PROCEDURE }\end{array}$} & P CAP & $3(100 \%)$ & 0 & \multirow{4}{*}{0.674} & $2(66.7 \%)$ & $1(33.3 \%)$ & \multirow{4}{*}{0.259} & $3(100 \%)$ & 0 & \multirow{4}{*}{0.408} \\
\hline & P EXT & $61(87.1 \%)$ & $9(12.9 \%)$ & & $64(91.4 \%)$ & $6(8.6 \%)$ & & $66(94.3 \%)$ & $4(5.7 \%)$ & \\
\hline & RC. PREP & $23(82.2 \%)$ & $5(17.8 \%)$ & & $24(85.7 \%)$ & $4(14.3 \%)$ & & $24(85.7 \%)$ & $4(14.3 \%)$ & \\
\hline & O.B.T. & $32(80 \%)$ & $8(20 \%)$ & & $30(75 \%)$ & $10(25 \%)$ & & $38(95 \%)$ & $2(5 \%)$ & \\
\hline \multirow{2}{*}{$\begin{array}{l}\text { PATENCY } \\
\text { FILE }\end{array}$} & YES & $38(76 \%)$ & $12(24 \%)$ & \multirow{2}{*}{0.552} & $37(74 \%)$ & $13(26 \%)$ & \multirow{2}{*}{0.719} & $45(90 \%)$ & $5(10 \%)$ & \multirow{2}{*}{0.638} \\
\hline & NO & $1(50 \%)$ & $1(50 \%)$ & & $1(50 \%)$ & $1(50 \%)$ & & $2(100 \%)$ & 0 & \\
\hline \multirow{2}{*}{ C.A. $(\mathrm{OH}) 2$} & YES & $59(83.1 \%)$ & $12(16.9 \%)$ & \multirow{2}{*}{0.774} & $63(88.7 \%)$ & $8(11.3 \%)$ & \multirow{2}{*}{0.411} & $65(91.5 \%)$ & $6(8.5 \%)$ & \multirow{2}{*}{0.542} \\
\hline & NO & $59(85.5 \%)$ & $10(14.5 \%)$ & & $56(81 \%)$ & $13(19 \%)$ & & $65(94.2 \%)$ & $4(5.8 \%)$ & \\
\hline \multirow{2}{*}{ NO. OF VISIT } & SINGLE & $29(82.7 \%)$ & $6(17.3 \%)$ & \multirow{2}{*}{0.215} & $27(77 \%)$ & $8(23 \%)$ & \multirow{2}{*}{0.871} & $34(97.1 \%)$ & $1(2.9 \%)$ & \multirow{2}{*}{0.032} \\
\hline & MULTIPLE & $9(64.3 \%)$ & $5(35.7 \%)$ & & $11(78.6 \%)$ & $3(21.4 \%)$ & & $11(78.6 \%)$ & $3(21.4 \%)$ & \\
\hline \multirow{4}{*}{ OPERATOR } & SP1 & $22(88 \%)$ & $3(12 \%)$ & \multirow{4}{*}{0.298} & $23(92 \%)$ & $2(8 \%)$ & \multirow{4}{*}{0.068} & $22(88 \%)$ & $3(12 \%)$ & \multirow{4}{*}{0.459} \\
\hline & SP2 & $28(73.7 \%)$ & $10(26.3 \%)$ & & $27(71 \%)$ & $11(29 \%)$ & & $35(92.1 \%)$ & $3(7.9 \%)$ & \\
\hline & GP1 & $19(90.5 \%)$ & $2(9.5 \%)$ & & $19(90.5 \%)$ & $2(9.5 \%)$ & & $21(100 \%)$ & 0 & \\
\hline & GP2 & $52(88 \%)$ & $7(12 \%)$ & & $53(90.1 \%)$ & $6(9.9 \%)$ & & $55(93.2 \%)$ & $4(6.8 \%)$ & \\
\hline
\end{tabular}

Table 4: Operative factors and the postoperative flare up.

\section{Discussion}

This study showed that postoperative flare-up was comparable to the reported postoperative flare-up in other studies (2\%-20\%) [8,9]. In contrast to another study, postoperative pain has been reported slightly more in men than women in this study [10]. However, the difference was not significant between the genders. This study result contradicts other study findings that reported gender as a factor that significantly influenced postoperative pain $[11,12]$. Yet, the reason for the slightly higher frequency of postoperative pain in male patients is not completely clear.

Another factor contributing to the higher frequency of postoperative pain in the present study is the patient's age. A higher incidence of postoperative pain was noticed in the middle age group patient than the teens and elderly patient's age groups. In contrast, a retrospective study showed a significant positive correlation of flare-ups with patients aged between 40 and 59 years [13]. However, the impact of patient age on postoperative flare-up incidence was not significant in many studies $[8,14]$. Interestingly, in this study, smoking was associated with a significantly higher incidence of postoperative pain and swelling. The association between smoking and endodontic disease has been shown in several studies [15].
The tooth category was not associated with a significantly higher incidence of postoperative pain in the first 24 hours. Other studies reported similar results [16,17]. Yet, this study's findings showed that posterior maxillary teeth had a greater frequency of postoperative pain than mandibular posterior teeth. These results are different from other research that reported more significant pain in the lower posterior teeth than upper posterior teeth. This finding could be linked to the complexity of the anatomy of the upper molars [17].

This study demonstrated that teeth with pulp necrosis and previously treated pulps had more significant postoperative pain. These results are similar to many other studies that reported higher postoperative pain incidence with necrotic pulps [18-22]. The discrepancy could be attributed to the criteria used to evaluate the postoperative pain or different treatment procedures.

This study's results also contradict previous studies that reported statistically significant correlations between the presence of periapical lesions and rates of postoperative pain after root canal treatments. However, the periapical lesion with a size larger than $5 \mathrm{~mm}$ was associated with a significantly higher incidence of postoperative swelling.

The result of this study showed that preoperative pain is significantly related to postoperative flare-up. Similar results 
were reported in another study [23].

Unlike many studies that reported insignificant differences in a postoperative flare-up between multiple visits and single visit appointments, this study showed that multiple visit treatment was associated with a significantly higher incidence of postoperative swelling [24,25]. Despite the insignificant results regarding the effects of the various obturation techniques on the incidence of the flare up, this study showed higher frequency of postoperative pain after obturation compared to cases treated by pulp extirpation only [24].

Surprisingly enough, the frequency of postoperative pain was higher in patients treated by the specialists than those who the general dental practitioners treated. This could be attributed to the level of difficulty and complexity of the cases seen by the specialist which was not considered in this study.

The complexity of the included cases in this study was not part of the inclusion criteria. Moreover, the treatment procedures were not standardized among the operators as shown in some researches [24,25]. These previously mentioned limitations that could negatively affect some of the association results. Future randomized controlled trials with well-defined inclusion criteria are recommended to identify post-endodontic flare-ups' contributing factors.

\section{Conclusion}

Despite the reported high incidence of post-operative pain with one of the specialist, the overall incidence of a postendodontic flare-up in this study was within the reported range of flare-up. Patient age group, smoking, preoperative pain, and size of the periapical lesion were the most determinant factors associated with higher postoperative flare incidence rates.

\section{References}

1. Tsesis I, Faivishevsky V, Fuss Z, Zukerman O (2008) Flare-ups after endodontic treatment: a meta-analysis of literature. J Endod 34(10): 1177-81.

2. Sipavičiūtė E, Manelienè R (2014) Pain and flare-up after endodontic treatment procedures. Stomatologija 16(1): 25-30.

3. American Association of Endodontics (2003) Glossary of endodontic terms. $7^{\text {th }}$ (Edn.), Chicago.

4. Seltzer S, Naidorf IJ (1985) Flare-ups in endodontics: I. Etiological factors. J Endod 11(11): 472-478.
5. Siqueira JF, Rocas IN (2003) Microbial causes of endodontic flareups. Int Endod J 36(7): 453-463.

6. Couper M, Tourangeau R, Conrad F, Singer E (2006) Evaluating the effectiveness of visual analog scales: A web experiment. Soc Sci Comput Rev 24(2): 227-245.

7. Van Wijk AJ, Hoogstraten J (2006) Reducing fear of pain associated with endodontic therapy. Int Endod J 39(5): 384-388.

8. Walton R, Fouad A (1992) Endodontic interappointment flare-ups: a prospective study of incidence and related factors. J Endod 18(4): 172-177.

9. Oginni AO, Udoye CI (2004) Endodontic flare-ups: comparison of incidence between single and multiple visit procedures in patients attending a Nigerian teaching hospital. BMC Oral Health 4(1): 4.

10. Polycarpou N, Ng YL, Canavan D, Moles DR, Gulabivala K (2005) Prevalence of persistent pain after endodontic treatment and factors affecting its occurrence in cases with complete radiographic healing. Int Endod J 38(3): 169-178.

11. YL Ng, Glennon JP, Setchell DJ, Gulabivala K (2004) Prevalence of and factors affecting post-obturation pain in patients undergoing root canal treatment. Int Endod J 37(6): 381-391.

12. Ryan JL, Jureidini B, Hodges JS, Baisden M, Swift JQ, et al. (2008) Gender differences in analgesia for endodontic pain. J Endod 34(5): 552-556.

13. Torabinejad M, Keltering JD, McGrav JC, Cummings RR, Dwyer TG, et al. (1988) Factors associated with endodontic interappointment emergencies of teeth with necrotic pulps. J Endod 14(5): 261-266.

14. Imura N, Zuolo ML (1995) Factors associated with endodontic flare-ups: a prospective study. Int Endod J 28(5): 261-265.

15. Duncan HF, Pitt Ford TR (2006) The potential association between smoking and endodontic disease. Int Endod J 39(11): 843-854.

16. Liddell A, Locker D (1997) Gender and age differences in attitudes to dental pain and dental control. Community Dent Oral Epidemiol 25(4): 314-318.

17. Segura Egea JJ, Cisneros Cabello R, Llamas Carreras JM, Velasco Ortega E (2009) Pain associated with root canal treatment. Int. Endod J 42(7): 614-620.

18. Mor C, Rotstein I, Friedman S (1992) Incidence 


\section{Open Access Journal of Dental Sciences}

of interappointment emergency associated with endodontic therapy. J Endod 18(10): 509-511.

19. Albashaireh ZSM, Alnegrish AS (1998) Postobturation pain after single- and multiple-visit endodontic therapy. A prospective study. J Dent 26(3): 227-232.

20. Mattscheck DJ, Law AS, Noblett WC (2001) Retreatment versus initial root canal treatment: factors affecting posttreatment pain. Oral Surg Oral Med Oral Pathol Oral Radiol Endodo 92(3): 321-324.

21. El Mubarak AH, Abu Bakr NH, Ibrahim YE (2010) Postoperative pain in multiple-visit and single-visit root canal treatment. J Endod 36(1): 36-39.

22. Keskin C, Demiryurek EO, Ozyurek T (2015) Postoperative Pain after Single-Versus-Multiple Visit Root Canal Treatment in Teeth with Vital or Non-Vital Pulps in a Turkish Population. Asian J Sci Res 8: 413-420.
23. DiRenzo A, Gresla T, Johnson BR, Rogers M, Tucker D, et al. (2002) Postoperative pain after 1-and 2-visit root canal therapy. Oral Surg Oral Med Oral Pathol Oral Radiol Endodontol 93(5): 605-610.

24. Yu YH, Kushnir L, Kohli M, Karabucak B (2021) Comparing the incidence of postoperative pain after root canal filling with warm vertical obturation with resinbased sealer and sealer-based obturation with calcium silicate-based sealer: a prospective clinical trial. Clin Oral Investig 25(8): 5033-5042.

25. Motlani M, Prasad PK, Makkad RS, Nair R, Khiyani S, et al. (2021) Incidence and Severity of Postoperative Pain Following Root Canal Treatment in Nonvital Pulps with Hand and Rotary Instrumentation Techniques in Chhattisgarh Population. J Pharm Bioallied Sci 13(Suppl 1): S319-S322. 